\title{
TRANSIÇÃO NA CARREIRA E A QUANTOFRENIA: UM ESTUDO DE CASO COM COORDENADORES DE MESTRADO E DOUTORADO DE UMA IES PRIVADA
}

\section{Resumo}

O artigo tem como objetivo compreender como gestores de programas de mestrado e doutorado de uma Instituição de Ensino Privada percebem a construção de suas carreiras, vivenciam a transição para assumirem o cargo de gestores e como lidam com a quantofrenia gerencialista. Para tanto, participaram da pesquisa oito professores doutores coordenadores Stricto Sensu de cursos de pós-graduação de uma IES privada. Os principais resultados evidenciaram que o trabalho se apresentou precarizado; na transição na carreira a maioria dos coordenadores não tem tempo de preparação para assumirem os novos cargos; a quantofrenia é intensa e a adesão ao projeto organizacional e aos índices da Capes redundam em difícil conciliação da vida pessoal e profissional.

Palavras-chave: transição, carreira, quantofrenia.

\section{Abstract}

The article aims to understand how the master's and doctoral's program managers in a Private Education Institution realize the construction of their careers, experience the transition and how they deal with managerial 'quantofrenia'. Therefore, participated in the survey eight doctors coordinators of a stricto sensu graduate courses in a private institution. The main results showed that the work is precarious; the transition in the career shows that they do not have time to prepare for assuming the new positions; the quantofrenia is intense and adherence to organizational design and contents of Capes redound to the difficult reconciliation of personal and professional life.

Key-words: transitions, career, 'quantofrenia'.

\footnotetext{
1 Professora da Escola de Administração e do Programa de Pós-graduação em Administração da Universidade Federal do Rio Grande do Sul - PPGA/UFRGS. (andreaoltr@gmail.com)
} 


\section{Introdução}

Uma série de estudos vem apresentando as transformações nas carreiras e no trabalho docente. Dentre eles destacam-se o de Rowe e Pinho (2011) que estudam o comprometimento com a carreira docente e as repercussões deste no desempenho e produtividade acadêmica. Além do fato do crescimento de professores de Instituições de Ensino Superior no Brasil, há importância do papel social de professores para o crescimento social, econômico e tecnológico do país.

Para construir suas carreiras, professores de ensino superior tem que se equilibrar entre uma série de atividades que compõem a sua vida profissional, tais como: preparação de aulas, mobilização de afeto com os discentes, atentar para ganhos de escala no que tange a produção acadêmica, dentre elas, orientação de mestrado e doutorado, bolsas produtividade, publicação em periódicos e participação e apresentação em congressos. O mesmo vale para coordenadores de curso de mestrado e doutorado, que, além de todas as atividades citadas anteriormente eles também têm de dar conta do gerenciamento dos cursos.

Esse último em especial, diz respeito a professores que trabalham em Stricto Sensu. Em geral, a Capes exige desses docentes uma série de publicações e envolvimentos com seus programas. Rowe e Pinho (2011) consideram esse envolvimento como comprometimento afetivo, momento em que o docente o faz porque gosta e se identifica tanto com a organização quanto com seu trabalho. Tal comprometimento também se apresenta no momento que o docente realiza uma transição na carreira e parte para a construção de sua trajetória profissional como gestor.

É sabido que vários docentes vêm investindo fortemente em suas carreiras. Acredita-se que para construírem suas carreiras eles tenham que trabalhar em finais de semana, adentram noites escrevendo artigos, e realizam pesquisas tanto nos horários contratuais de trabalho quanto além desses horários. Mesmo que o trabalho docente constitua-se num espaço de identidade e que as possibilidades de autonomia e prazer no trabalho sejam intensas, há que se considerar também que tensões, ansiedades e preocupações são emoções que rondam a vida profissional docente. Paixão, Melo e Silva (2011) consideram que há elementos para contribuir a isso: tempo para preparação de aulas e pesquisas; carência de reconhecimento entre professor e aluno e dificuldades no equilíbrio entre vida pessoal e profissional. Tal fato também é acompanhado pelo aumento de IES privadas no Brasil, marcado por orientações mercantilistas. Se a educação é menosprezada decorre disso uma série de malefícios na relação ensino-aprendizagem.

Em IES privadas os indicadores de performance podem ser altos e associados a uma pressão sem precedentes no que se refere a trabalhadores do setor da educação. Sobre o estudo dos indicadores associados à instrumentalização do ser humano chama-se quantofrenia a obsessão por números, geralmente fazendo as pessoas perderem o senso da medida, especialmente por colocá-las a serviço da organização.

Assim, esse artigo tem o objetivo de compreender elementos que tragam para o debate associações entre gestão, quantofrenia e transição na carreira. Como pergunta de pesquisa, tem-se: Como gestores de programas de mestrado e doutorado de uma Instituição de Ensino Privada percebem a construção de suas carreiras, vivenciam a transição para assumirem o cargo de gestores e como lidam com a quantofrenia gerencialista? 


\section{Revisão da Literatura}

Nessa seção serão apresentadas as questões da transição na carreira e sobre a quantofrenia e a gestão gerencialista.

\subsection{Transição Profissional}

A transição na carreira ocorre quando a pessoa efetua um movimento que implica especialmente em assumir uma nova identidade profissional (VELOSO e DUTRA, 2010; VELOSO, 2012). Por uma nova identidade profissional entende-se não somente uma mudança de função, mas, principalmente um processo que, segundo o estudo de Quishida (2007) pode se apresentar pela passagem pelos estágios da carreira (entrada, avanço, reavaliação, reforço e nova entrada precedida por ruptura); passagem pelas fases (pré-transição, descontentamento crescente, crise, redirecionamento e reestabilização). Um indivíduo pode passar por uma, algumas, ou todas as fases, ou seja, pode vivenciar a transição de maneiras diferentes.

O sentimento de transição na carreira é experimentado de modo ambíguo uma vez que pode ao mesmo tempo oferecer satisfação profissional e status, e também angústias especialmente quando há progressão entre estágios na carreira, que envolvem movimento de uma função para outra (VELOSO, 2012). A transição também requer assumir novas responsabilidades e possível ambigüidade nas tomadas de decisão que envolve clientes, colegas ou subordinados.

A transição de papel profissional pode ocorrer mediante a mudança de um cargo para outro (VELOSO, 2012). Tal acontecimento é um desafio especialmente quando a mudança envolve níveis hierárquicos diferentes. A expectativa, diz Veloso (2012), cumpre um dos estágios do processo de transição e é seguida do estágio de conscientização durante os primeiros dias ou semanas do exercício da nova função para promover um ajuste entre as expectativas da pessoa referente ao novo cargo.

Para Veloso e Dutra (2010) a transição na carreira é um processo doloroso que não se restringe a mudança de função. Para eles "mudar de função é mudar de roupa e a transição na carreira é arrancar a pele e viver em carne viva até uma nova pele recobrir nossas feridas" (VELOSO e DUTRA, 2010, p. 103). Considera-se que para viver a transição na carreira é necessário ter mobilidade tanto física quanto psicológica (SULLIVAN e ARTHUR, 2006), próprias da carreira sem fronteiras. A mobilidade psicológica refere-se a real possibilidade de mudança, que de um certo modo, sustenta a mobilidade física.

Para Louis (1980) a transição de carreira é o período durante o qual um indivíduo está ou mudando ou redirecionando suas funções ou orientações. Desse modo, a transição pode se dar por busca de mais momentos com a família, mudança de estilo de vida, busca de sucesso profissional, reorganização do espaço e relações familiares e também por demissão (VELOSO, 2012). Quanto menor a preparação para a transição da carreira maior é a responsabilidade do indivíduo pela condução da sua vida profissional. Em geral o processo de adaptação as novas realidades são carregadas de desconforto (VELOSO, 2012) e de mobilização subjetiva para a construção dessa nova perspectiva (OLTRAMARI e GRISCI, 2012).

Para Veloso (2012) é necessário explorar o fato de que as transições impõem a transposição de certas fronteiras e que para dar conta dessas transições a mobilização subjetiva é a mais requisitada pelos sujeitos. Isso porque o movimento que diz respeito às fronteiras objetivas (movimento entre funções, organizações e profissões) remete menos para a responsabilidade do sujeito e mais para a responsabilidade das organizações.

As transições na carreira se dão especialmente em momentos de repensar os seus rumos, como por exemplo, repensar prioridades na carreira em relação às relações familiares (OLTRAMARI e GRISCI, 2013); necessidades após a aposentadoria (MATOS e FONTOURA, 
2013) transição entre profissões (KILIMNIK, CORRÊA, OLIVEIRA, 2009); mulheres que freiam a carreira para cuidar dos filhos, intitulada carreira caleisdoscópica (MAINIERO e SULLIVAN, 2005).

A transição na carreira implica também a busca por resultados decorrentes de uma intensa dedicação ao trabalho, na medida em que muitas vezes o sujeito se submete a intensas jornadas de trabalho, ao alcance de indicadores de performance, e aumento de responsabilidades, que via de regra se traduzem na quantificação do trabalho, denominado por Gaulejac (2007) de quantofrenia gerencialista, discussão apresentada no próximo item.

\subsection{Quantofrenia e a Gestão Gerencialista}

Os estudos que vem problematizando o conceito de sucesso profissional e como a gestão vêm contribuindo para sua disseminação têm sido recorrentes nas pesquisas em administração (ITUASSU e TONELLI, 2014; GAULEJAC, 2007) embora esse tema seja foco de atenção em proporções maiores fora do ambiente acadêmico (ITUASSU e TONELLI, 2014) tal como a literatura pop management (WOOD JR. e PAULA, 2002) aponta, ao qual inclui livros, revistas e jornais de gestão e que tem o objetivo de reproduzir a ideologia empresarial.

Associado a lógica do sucesso e de sua reprodução acrítica, a cultura do alto desempenho se impõe como modelo de eficiência para os trabalhadores. A gestão gerencialista, que se apresenta como eficaz e de perfeito desempenho invade a vida dos sujeitos e os põe sobre pressão, especialmente para atingir os indicadores de performance. A gestão gerencialista, para Gaulejac (2007, p. 36) "é uma ideologia que traduz as atividades humanas em indicadores de desempenhos, e esses desempenhos em custos ou em benefícios. Constroem uma representação do humano como um recurso a serviço da empresa, contribuindo, assim, para sua instrumentalização". A gestão gerencialista, para além de regras racionais, de prescrições precisas e de instrumentos de medida sofisticados também promove o julgamento das regras de forma arbitrária. Por trás da racionalidade fria dos números dissimula-se a quantofrenia, que se traduz pela obsessão por números, geralmente fazendo as pessoas perderem o senso da medida (GAULEJAC, 2007) e colocá-las a serviço da empresa/organização.

Estudos que vêm apresentando os diversos problemas originados pela interiorização da rentabilidade e da busca pelo sucesso (OLTRAMARI, GRISCI, WEBER, 2011; TANURE, CARVALHO NETO, ANDRADE, 2007) dizem das consequências danosas à saúde e as relações familiares, especialmente quando o desempenho e a rentabilidade são medidos em curto prazo. Os dirigentes são cada vez mais submetidos às expectativas da organização, cuja motivação principal é a financeira e são também sujeitados a precarização no trabalho, tal como horários irregulares, trabalho noturno, desorganização da vida familiar e de seus ritmos biológicos (GAULEJAC, 2007).

Os fundamentos da gestão gerencialista são baseados na eficácia da ação, muito mais do que na pertinência das ideias. Os gestores tornam-se pessoas que prescrevem modelos e fundamentados sobre a eficácia da ação esquecem qualquer possibilidade de reflexão acerca da coletividade.

É possível mencionar, desse modo, que todos os gestores são, de alguma maneira, influenciados pelas questões relativas ao trabalho. Além disso, muitos gestores também são responsáveis por sustentar e reproduzir a discursividade que sustenta a ideologia gerencialista. Os gerentes, ou ainda denominados managers, segundo Gaulejac (2007), passam a serem figuras fundamentais nesta reprodução ideológica. Davel e Melo (2005, p. 29), ao trabalharem o gerente como homo administrativus, destacam que este se torna o personagem central para a compreensão da sociedade contemporânea, na medida em que produz e reproduz "[...] todo um sistema de descrição, de explicação e de interpretação do mundo a partir das categorias 
do campo da Administração", sendo os grandes responsáveis pela sustentação da dinâmica, ou mesmo do sucesso empresarial.

Há de se considerar, nesse sentido, que os gestores, assim como outros trabalhadores, estão sujeitos a diversos fatores que influenciam diretamente no seu modo de trabalhar. Davel e Melo (2005, p. 331), baseados nos estudos de Watson e Harris, apontam que

[...] Nas empresas, as pessoas são convidadas a se apresentar de determinada maneira, suprimindo ou dissimulando seus sentimentos ou ainda permitindo que tais sentimentos sejam expressos somente em determinadas situações ou formas específicas - segundo as regras implícitas da organização. Nesse sentido, os gestores desempenham um trabalho emocional importante, controlando a si mesmos, cuidando para se apresentar de forma apropriada, lidando com o sentimento dos subordinados e de superiores, conduzindo e tentando solucionar conflitos, motivando e encorajando os demais. Podemos então nos questionar sobre os fardos que esse trabalho emocional representa para os gerentes, mas também sobre o que acontece com os sentimentos que eles absorvem, suprimem e dissimulam.

Acredita-se que os gestores de Stricto Sensu venham passando pela quantificação do seu trabalho, e esse artigo têm, dentre um de seus objetivos mostrar e refletir como a quantificação vem se apresentando.

\section{Procedimentos Metodológicos}

O presente artigo é resultado de uma pesquisa qualitativo-descritiva que teve como objetivo identificar a seguinte questão: Como gestores de programas de mestrado e doutorado de uma Instituição de Ensino Privada percebem a construção de suas carreiras, vivenciam a transição para assumirem o cargo de gestores e como lidam com a quantofrenia gerencialista?

Participaram da pesquisa oito professores doutores coordenadores Stricto Sensu de cursos de pós-graduação na IES a ser caracterizada posteriormente. Segundo o portal online do coordenador Stricto Sensu da IES em análise, compete a ele gerenciar o programa de pósgraduação, com permissão para criar novas turmas, gerenciar o processo seletivo, cadastrar o corpo docente, formular o calendário acadêmico, bem como emitir relatórios gerenciais. Apresenta-se no quadro a seguir o perfil dos participantes:

Quadro 1: Perfil dos Participantes

\begin{tabular}{|c|c|c|c|c|}
\hline Código & $\begin{array}{c}\text { Área de } \\
\text { Atuação }\end{array}$ & Título & $\begin{array}{c}\text { Tempo de } \\
\text { Universidade }\end{array}$ & Sexo \\
\hline Coord. E1 & Educação & Doutor & 35 anos & Masculino \\
\hline Coord. E2 & Agronomia & Doutor & 22 anos & Feminino \\
\hline Coord. E3 & $\begin{array}{c}\text { Engenharia } \\
\text { Civil }\end{array}$ & Doutor & 22 anos & Masculino \\
\hline Coord. E4 & Letras & Doutor & 8 anos & Feminino \\
\hline Coord. E5 & História & Doutor & 27 anos & Feminino \\
\hline Coord. E6 & $\begin{array}{c}\text { Engenharia } \\
\text { Mecânica }\end{array}$ & Doutor & 22 anos & Masculino \\
\hline Coord. E7 & $\begin{array}{c}\text { Envelhecimento } \\
\text { Humano }\end{array}$ & Doutor & 17 anos & Masculino \\
\hline Coord. E8 & Odontologia & Doutor & 2 anos & Feminino \\
\hline
\end{tabular}

Dados da Pesquisa (2013). 
Conforme o quadro 1 representado a média de tempo dos professores na instituição é de 21,8 anos, sendo que a maioria deles relataram durante a pesquisa terem feito parte da criação do programa. A ordem dos entrevistados se deu de forma aleatória e por disponibilidade dos mesmos, não levando-se em consideração o sexo dos participantes, nem sua ordem gerada, sendo ignorado o fato coincidente de se ter quatro homens e quatro mulheres entrevistadas. A idade de cada participante não está descrita no quadro por decisão dos autores. A técnica de coleta dos dados foi feita por meio de uma entrevista individual semi-estruturada. Os coordenadores foram contatados por um e-mail que explicava o objetivo da pesquisa e um horário para a entrevista marcado, se aceito o convite. Os coordenadores foram entrevistados em seu local de trabalho, dentro da IES.

As entrevistas com os coordenadores buscaram aprofundar o conhecimento sobre como eles conduzem suas carreiras, através do roteiro de pesquisa que abordava questões sobre a construção de suas carreiras; a condução das exigências de produtividade; dificuldades enfrentadas, tanto na vida pessoal quanto na profissional; necessidades de frear a carreira; e possíveis mudanças, sendo que a entrevista foi conduzida ao modo que fluíam os assuntos abordados anteriormente. As realizações das entrevistas permitiram revelar emoções e desabafos. As entrevistas foram gravadas com a autorização dos participantes e posteriormente transcritas e interpretadas. Os dados obtidos foram sendo analisados e ordenados de forma pertinente à revisão de literatura, sendo os mesmos lidos e escritos com busca a entender a condução e dinâmica da carreira dos coordenadores Strictu Sensu.

\section{Análise dos Resultados}

Neste item encontram-se a apresentação e análise dos resultados do estudo. As categorias foram tanto definidas antes do trabalho de campo, na fase exploratória da pesquisa quanto após a coleta de dados, proposta sugerida por Minayo (2001). Em seguida, foram comparadas tais categorias e após sucessivas reflexões a partir da base teórica foram estabelecidas as categorias finais de análise, quais sejam: Gestão e trabalho na IES em análise, transição profissional e quantofrenia gerencialista.

\subsection{Gestão e Trabalho na IES em Análise}

A IES em análise tem 45 anos de existência, sendo que em 1967 possuía sete faculdades isoladas e em 1968 decreta-se o reconhecimento como Universidade. Sua ênfase é no conceito de Universidade Pública não Estatal, que tem como aspectos característicos: a origem na comunidade local, a escolha dos dirigentes pela comunidade universitária, a importância dos serviços comunitários e a contribuição ao desenvolvimento da região. $\mathrm{O}$ modelo da Universidade é comunitária, modelo este incluído na Constituição Federal de 1988. O primeiro estatuto da Universidade em análise já referia que sua pesquisa deveria compreender os problemas socioeconômicos da comunidade em que esta IES estivesse inserida. Desse modo é que surgiram seus programas de mestrado e doutorado, como um modo de também atender as demandas da região em que se localiza.

Em relação à composição da carga horária dos professores vinculados a stricto sensu ela é prioritariamente destinada aos programas de pós-graduação ao qual estão vinculados. Para os professores que não estão associados a programas de pós-graduação ela é composta por períodos parciais, que dizem respeito aqueles que têm sua carga horária de trabalho até 20 horas semanais e aqueles que têm carga horária integral, o que representa 40 horas semanais registradas em carteira de trabalho. Tais horas são preenchidas com aulas na graduação, prioritariamente.

No entanto, mesmo que tenham relativo tempo para pesquisa os coordenadores referem 
que "fui percebendo ao longo do tempo que o que existe aqui não são pesquisadores, e sim professores que fazem pesquisas nas horas de folga" (E3). A falta de professores para compor o quadro docente nos programas de mestrado e doutorado faz com que alguns deles tenham que assumir mais turmas do que o que seria permitido, inclusive por regras da IES, tal como revela um dos entrevistados: "Além da coordenadoria, eu tenho cinco turmas na graduação, um reflexo é a falta de tempo" (E6).

A IES em análise está inserida numa região com um grande número de centros universitários e faculdades isoladas, fato que a deixa vulnerável quanto ao preenchimento de turmas. Por vezes a quantidade de alunos não excede o número de vagas ofertadas e isso recai sobre a composição das horas dos professores. Por outro lado, quando o número de alunos excede a oferta de vagas a mesma instituição aloca um maior número de aulas para os professores, com o objetivo de aumentar a produtividade dos atuais professores contratados. Tal fato é perceptível na fala de um dos coordenadores: "Há a entrada de muitos alunos por ano no [nome do curso] a [nome da IES] está achando ótimo, altamente rentável, mas tem coisas que acabam sendo prejudicadas, e aí volta, por exemplo, a angústia dos índices de produtividade. Esse é o dilema. Com os alunos a gente está conseguindo um bom feedback, o problema é que você acaba se sentindo frustrado com os índices da Capes" (E6). Percebe-se, portanto, que a fala do coordenador também reflete a angústia de seus colegas de trabalho. $O$ medo se dá especialmente porque se houver o descredenciamento numa IES particular, ele resulta em aumento da carga horária na graduação e perda de horas de pesquisa.

Em IES particular a pesquisa requer um alto investimento e na maioria das vezes não tem um retorno financeiro imediato, como, por exemplo, o retorno que a graduação traz. Tal fato faz com que a carreira de coordenadores e professores fiquem subordinadas as decisões dos gestores da IES que dizem respeito a redução de mensalidades, reorganização e por vezes redução de carga horária, resultando na indefinição da vida profissional destes. A fala a seguir ilustra tal indefinição: "talvez um desafio para quem está na gestão é a sustentação dos programas de pesquisa, a gente sabe que eles são deficitários e no ano passado a reitoria teve que tomar uma atitude de reduzir os custos dos cursos nas áreas de ciências humanas, porque o valor da mensalidade ultrapassava o que os alunos em média recebem como professores de escolas de ensino médio e fundamental. Essa redução recai no professor". Enquanto há uma identificação com os interesses da IES e uma adesão às normas e aos valores do sistema capitalista, há também tanto a condição salarial quanto as condições de trabalho submetidas às imprevisibilidades da carreira do professor e do coordenador.

\subsection{Transição na Carreira}

Em linhas gerais a transição na carreira para coordenadores se apresentou em formas de dilemas que tiveram que ser resolvidos de forma rápida. Os dilemas envolveram desde aceitar ou não o cargo de coordenador, a difícil conciliação entre a vida acadêmica e administrativa até a complexa escolha entre a dedicação do tempo a vida profissional ou pessoal. Em geral os coordenadores relataram que repensar os rumos da carreira não foi feito de modo reflexivo, mas imposto, uma vez que tornar-se professor e pesquisador, não foi uma decisão racional, mas que as oportunidades do meio é que definiram a escolha.

A preparação para a transição de carreira acontece a partir do momento que a aposentadoria está se aproximando. Tal como E2 comenta que está na coordenação há um ano e se programa para se aposentar em quatro anos, que caracteriza uma ruptura com a identidade profissional de coordenadora, pesquisadora e professora.

O dilema do trabalho do coordenador reside em exigir produção dos pesquisadores e cumprir normas da Capes e regimentos, bem como amenizar conflitos internos. As atribuições dos coordenadores geralmente abrangem várias atividades, dentre elas oferecer condições 
aos professores para pesquisar, embora saibam que isso não depende só deles, o que resulta num dilema. Alguns coordenadores apontaram que se pudessem retroagir no tempo, não assumiriam atividades administrativas, mesmo conscientes de que a gestão deve ser exercida por alguém do quadro dos professores, E1 relata que: "o que frustra é que você faz um monte de coisa, mas quando vai fazer o somatório, o que sobrou? Hoje se eu tivesse a possibilidade de voltar atrás, muitas funções administrativas eu não teria assumido, pois são funções que não qualificam, embora a gente saiba que alguém tem que fazer. Muitas vezes eu me pergunto pra que serve tudo isso?". Os coordenadores se sentem numa encruzilhada entre o tempo para se fazer pesquisa e as exigências inevitáveis de cumprir as regras. Dessa forma eles percebem que há um ônus em vivenciar essa transição, tal como E5 refere: "Assumi esse cargo por um compromisso que você tem com a instituição, porque na verdade é só ônus".

A preparação para a transição é inexistente. Quando eles assumem o cargo de coordenação, geralmente são solicitados a ocupá-lo subitamente, como relata o E5: "nunca senti necessidade de frear a minha carreira, única vez que me senti mal foi quando voltei da minha licença maternidade e o coordenador largou tudo e disse que quem assumia era eu, isso foi completamente inesperado e difícil, mas consegui dar conta".

A transição requer a conciliação tanto com as atividades do cargo anterior quanto do novo cargo, o que muitas vezes acarreta em sobrecarga. Para auxiliá-los eles devem contar com uma equipe de apoio, o que nem sempre é possível, uma vez que a gestão não permite essas contratações, para não gerar custos, o que acarreta também no acúmulo de funções para o coordenador. O E7 refere tal fato: "nem sempre é possível compatibilizar as duas coisas, ainda mais quando o programa é novo, pois tem que ser implantado internamente, tem que criar um fluxo administrativo, precisa de pessoal de apoio competentes ao teu lado. Então nem sempre é possível combinar a função administrativa com a função acadêmica".

Tudo isso resulta numa busca incessante pelo atingimento de metas, necessitando utilizar de tempo além do contratado para cumprir tanto com a função acadêmica quanto de gestão, para atingir os índices de produtividade seus e do grupo, muitas vezes levandoos a uma busca excessiva por números. O E5 refere-se a tal fato na fala: "o produtivismo produz dilemas. Temos que produzir no grupo, porque se um do grupo falhar prejudica todos. A questão de você ser coordenadora de docente, não conta nada no teu lattes. Os avaliadores só visualizam o que eu produzi". Esses elementos dizem respeito ao que Gaulejac (2007) chama de quantofrenia gerencialista item que será abordado a seguir a partir das vivências dos coordenadores.

\subsection{Quantofrenia}

Os resultados dos coordenadores são avaliados e quantificados por índices instituídos pela Capes. Essa busca por índices representa o que Gaulejac (2007) traduz como gestão gerencialista, ideologia baseada em indicadores de desempenhos, transformados em custos ou em benefícios, resultantes das atividades humanas que possuem a representação de que o humano é um recurso da empresa, podendo ser instrumentalizado. Fato esse que conduz a quantofrenia, ou seja, busca obsessiva pelos números.

Tal busca obsessiva provoca nos gestores uma ansiedade que só é aplacada quando os números são alcançados. Uma vez alcançados inicia-se um novo ciclo, onde se reprisa essa busca incessante. Todos os coordenadores se apresentaram conscientes de que é desse ciclo que depende suas carreiras. Um entrevistado refere que "isso gera uma angustia, porque a cada ano tem que apresentar indicadores e tudo mais, e muitas vezes esses ficam aquém do que a gente esperava, e realmente isso é muito angustiante" (E6). As verbas de financiamento tanto estadual e federal quanto da própria instituição estão associadas à quantidade de publicação, o que acarreta na sua hipersolicitação pelo trabalho. Outro também relata que: "a 
vida da gente é em função daquilo que a Capes quer, tem que ter tantos produtos indicadores 1 , outro tanto indicador tal. Somos números, e às vezes o que acontece é que eu perco a qualidade, eu poderia trabalhar melhor se pudesse publicar um artigo por ano" (E4).

É nesse sentido que alguns coordenadores se apresentaram com medo de ficarem, tal como eles relatam "acomodados" (E6; E3). Há o medo da acomodação e do apego ao lugar como um contraponto ao imaginário do sucesso, que diz respeito à busca do status $\mathrm{e}$ desapego afetivo com a IES que trabalham.

A quantofrenia atinge também, além da busca constante pelos números, os estilos de vida em família. A E2, por exemplo, optou por aumentar a sua produção e reduzir suas idas à congressos, de modo que pudesse ficar mais com a família:

"Essa opção de não ir tanto a congressos e eventos é para um maior relacionamento com meus filhos e meu marido. Já teve situações que eu tive que repensar e decidir por um caminho ou outro, quando comecei a ser pesquisadora precisei decidir, entre ser a pesquisadora, ou ser uma pesquisadora conciliando família, optei pela segunda alternativa".

Dependendo da área da pós-graduação, os pesquisadores e coordenadores ficam a mercê de fatores que vão além do seu controle, como é o caso da E2: "Eu tive dois anos perdidos em termos de dados, que foram as duas últimas secas". Nesse caso a medição do trabalho independe do pesquisador, assim como as condições de trabalho também. Esses casos extrapolam a vontade do pesquisador, o tornando falível. Outro fator que extrapola o controle do coordenador é o fato de muitos estudantes necessitarem trabalhar, especialmente para pagarem as mensalidades, uma vez que as bolsas de estudos são escassas, o que resulta na falta de tempo para participar das pesquisas instituídas nos programas de pósgraduação.

A quantofrenia produz dilemas que convergem para uma impossibilidade de decisão satisfatória. Tal como um coordenador descreve a sua difícil escolha entre incentivar publicações em revistas que requerem pesquisas de alta tecnologia e tem alto fator de impacto, mas sem aplicabilidade em curto prazo, ou publicar artigos que tenham uso imediato para a agricultura, por exemplo, mas em revistas de baixo impacto.

A quantofrenia também está associada à precarização do trabalho no que se refere ao acúmulo de funções, como explicita o E1: "muitas vezes não se tem condições para tanta produção, embora você tenha os horários de pesquisa, o cotidiano de uma universidade envolve muita coisa, então se você quiser dar conta dessa demanda, da exigência que a vida acadêmica faz, você acaba sacrificando horários, pois você também tem reuniões para participar, funções burocráticas e administrativas".

A busca por números e resultados e por um modelo de eficiência (GAULEJAC, 2007) tem consequências danosas à saúde, a coletividade e relações familiares. As falas a seguir ilustram vivências da quantofrenia: "muitas pessoas acabam se esgotando e até adoecendo, vários colegas se auto-excluiram do programa. O que mais se acentua é necessitar do resultado produto, quando na verdade você precisaria de tempo para um trabalho de boa qualidade. Acho que a instituição de ensino está muita voltada à impessoalidade, você é apenas um número" (E1). Os pesquisadores acabam assumindo um problema que seria da organização do trabalho. A situação de exclusão fica no anonimato, não aparecendo, desse modo o real problema. É importante salientar que nem sempre a reivindicação por uma melhor organização do trabalho é bem vista, tanto pela instituição quanto pelos colegas. A exigência da rentabilidade e da quantofrenia aguda recai nas relações familiares e no tempo destinado ao descanso: "muitas vezes tenho que abrir mão de alguma coisa para cumprir prazos em publicações, e sempre abro mão da minha vida pessoal, das minhas noites e madrugadas, 
mas eu preciso, o programa precisa" (E4). Os ganhos de produtividade acontecem na intensificação do trabalho e nesse caso pela rentabilização do tempo de descanso também. $O$ espaço, que antes era do repouso, é agora também local de trabalho.

Com a ascensão na carreira, os cuidados com a saúde e os horários de descanso diminuem. Por sua vez, a preocupação e a situação de desgaste físico e mental contribuem para o adoecimento dos coordenadores: "há interferências do meu trabalho na minha saúde, essa fase eu estou totalmente estressada, eu durmo com dor de cabeça, acordo com dor de cabeça, ainda não consigo ponderar meus limites" (E4).

Amobilização total do individuo em prol do trabalho redunda em "sintomas de superatividade" (GAULEJAC, 2007), fato que se desdobra numa autocobrança, tal como relata E5: "eu me sinto pior em relação a minha carreira quando eu vejo o meu lattes e percebo que ele poderia estar muito melhor". Há um mal-estar provocado pela hipersolicitação relativa à produção e publicação, tal como expõem o E5: "é uma angústia constante, porque além de produzir e publicar, você precisa publicar em veículos qualificados".

Adicionalmente, é interessante notar como alguns coordenadores se queixam das altas metas a serem alcançadas. No entanto eles assimilam o discurso organizacional o reproduzindo para si e para os pares.

\section{Considerações Finais}

$\mathrm{Na}$ IES em análise o trabalho se apresentou precarizado para os coordenadores. A pesquisa não é vista como principal objetivo, especialmente porque a concorrência entre o ensino privado faz com que os recursos limitados sejam destinados essencialmente à graduação. Em relação à transição na carreira percebeu-se que a maioria dos coordenadores não tem um tempo de preparação para assumirem os novos cargos. Desse modo os dilemas se apresentam de forma constante: ao assumir a função administrativa, inevitavelmente a carreira acadêmica é freada.

A quantofrenia que se apresenta na IES é intensa. A adesão ao projeto organizacional e aos índices da Capes redundam em difícil conciliação da vida pessoal e profissional, na precarização do trabalho pelo acúmulo das funções e por fim numa ansiedade pelos resultados alcançados. Também traz a noção de que os coordenadores são vulneráveis ao tempo, as decisões e as condições físicas e psicológicas, fato que pode se apresentar como uma resistência à aceleração do trabalho.

Há também uma auto-cobrança por parte dos coordenadores o que torna difícil pensar que tanto pesquisadores quanto professores são falíveis. Há que se considerar que um pesquisador é falível e o excesso de atividades pode ocasionar em adoecimento no trabalho. Assim, debruçar olhares sob seu trabalho pode auxiliá-los a tornar tanto suas pesquisas quanto suas aulas com mais qualidade.

\section{Referências}

DAVEL, Eduardo; MELLO, Marlene Catarina. Gerência em ação: singularidades e dilemas do trabalho gerencial. São Paulo: Ed. FGV, 2005.

GAULEJAC, Vincent. Gestão como doença social. São Paulo: Idéias e Letras, 2007.

ITUASSU, Cristiana Trindade; TONELLI, Maria José. Sucesso, mídia de negócios e a cultura do management no Brasil. Cadernos EBAPE (FGV), v. 12, p. 86-111, 2014.

KILIMNIK, Zélia Miranda; CORRÊA, Maria Lúcia R.; OLIVEIRA, Luiz Cláudio V. O. Da gerência para a docência: uma transição de carreira cada vez mais freqüente na área de 
administração. In: II Encontro de Gestão de Pessoas e Relações de Trabalho, 2009, Curitiba, Anais... Curitiba: 2009. CD-ROM.

LOUIS, M. R. Career Transitions: varities and commonalities. Academy of Management Review, vol. 5, n. 3, p. 329-340, 1980.

MAINIERO, Lisa; SULLIVAN, Sherry. Kaleidoscope careers: an alternative explanation for the opt-out revolution. Academy of Management Executive, v. 19, n. 1, p. 106-123, 2005.

MATOS, Catarina Seco ; FONTOURA, Daniele dos Santos . Envelhecimento da População e Mercado de Trabalho: a opção do Empreendedorismo notas para Portugal. In: XXXVII ENANPAD, 2013, Rio de Janeiro. Anais do XXXVII Enanpad.

MINAYO, Maria Cecília de Souza (Org.). Pesquisa social: teoria, método e criatividade. Petrópolis: Vozes, 2001.

OLTRAMARI, Andrea ; GRISCI, C. L. I. . Dilemmas and Career Development of Brazilian Bank Executives. African Journal of Business Management, v. 7, p. 1161-1173, 2013.

OLTRAMARI, Andrea ; GRISCI, C. L. I. ; Weber, Lílian . Carreira e relações familiares: dilemas de executivos bancários. Revista Mal-Estar e Subjetividade (Impresso), v. XI, p. 101133, 2011

OLTRAMARI, Andrea; GRISCI, Carmem Ligia lochins. Trajetórias e Transições nas Carreiras de Executivos Bancários. Revista Gestão e Tecnologia, v. 12, p. 126-150, 2012.

PAIXÃO, Roberto Brazileiro; MELO, Daniel Armond Reis; SILVA, Jader Cristino de Souza. Assédio Moral na relação aluno-professor: uma análise a partir do discurso coletivo de professores universitários. In: XXXV Encontro da Associação Nacional dos Programas de Pós-graduação em Administração, 2011, Rio de Janeiro, Anais... Rio de Janeiro: 2011. CDROM.

QUISHIDA, Alessandra. Adptação à transição de carreira na meia idade: um estudo exploratório sob o enfoque do locus de controle. 2007. Dissertação (Mestrado em Administração) - Departamento de Administração. Faculdade de Economia, Administração e Contabilidade da Universidade de São Paulo, São Paulo.

ROWE, Diva Ester Okazaki; PINHO, Ana Paula Moreno. Múltiplos vínculos com o trabalho e suas relações com o desempenho: um estudo entre professores do ensino superior no Brasil. In: XXXV Encontro da Associação Nacional dos Programas de Pós-graduação em Administração, 2011, Rio de Janeiro, Anais... Rio de Janeiro: 2011. CD-ROM.

SULLIVAN, Sherry; ARTHUR, Michael. The evolution of the boundaryless career concept: examining physical and psychological mobility. Journal of Vocational Behavior, n.69, p. 19-29, 2006.

TANURE, Betania; CARVALHO NETO, Antonio; ANDRADE, Juliana. Executivos: sucesso e (in)felicidade. Rio de Janeiro: Elsevier, 2007.

VELOSO, Elza Fátima Rosa. Carreiras sem fronteiras e transição professional no Brasil: desafios e oportunidades para pessoas e organizações. São Paulo: Atlas, 2012.

VELOSO, Elza Fátima Rosa; DUTRA, Joel Souza. Processo de Transição de Carreira. In: DUTRA, Joel Souza (Org.). Gestão de carreiras na empresa contemporânea. São Paulo: Atlas, 2010.

WOOD JR, T.; PAULA, A. P. P. Pop-management: pesquisa sobre as revistas populares de gestão no Brasil. In: ENCONTRO DA ANPAD, 26, 2002, Salvador. Caderno de Resumos do..., Salvador: Anpad, 2002. 